Rabaska

Revue d'ethnologie de l'Amérique française

\title{
Gérald Thomas (1940-2005)
}

\section{Ronald Labelle}

Volume 4, 2006

URI : https://id.erudit.org/iderudit/201764ar

DOI : https://doi.org/10.7202/201764ar

Aller au sommaire du numéro

Éditeur(s)

Société québécoise d'ethnologie

ISSN

1703-7433 (imprimé)

1916-7350 (numérique)

Découvrir la revue

Citer ce document

Labelle, R. (2006). Gérald Thomas (1940-2005). Rabaska, 4, 89-91.

https://doi.org/10.7202/201764ar

Ce document est protégé par la loi sur le droit d'auteur. L'utilisation des services d'Érudit (y compris la reproduction) est assujettie à sa politique d'utilisation que vous pouvez consulter en ligne.

https://apropos.erudit.org/fr/usagers/politique-dutilisation/
Cet article est diffusé et préservé par Érudit.

Érudit est un consortium interuniversitaire sans but lucratif composé de l'Université de Montréal, l'Université Laval et l'Université du Québec à Montréal. Il a pour mission la promotion et la valorisation de la recherche. https://www.erudit.org/fr/ 


\section{Nécrologie}

\section{Gérald Thomas (1940-2005)}

Né au Pays de Galles en 1940, Gérald Thomas s'est rendu à Terre-Neuve en 1964 pour enseigner le français à la Memorial University of Newfoundland. Il rencontra alors le fondateur du département de Folklore de cette université, Herbert Halpert, qui deviendrait plus tard son directeur de thèse. En 1970, Thomas rédigea un mémoire de maîtrise consacré à un recueil de contes français du XVI ${ }^{\mathrm{e}}$ siècle. Son mémoire, intitulé The Tall Tale and Philippe d'Alcripe, fut publié en 1977.

À partir de 1971, Thomas s'est lancé à la recherche des traditions orales françaises sur la côte ouest de Terre-Neuve. Ses premières enquêtes furent si fructueuses qu'il choisit de

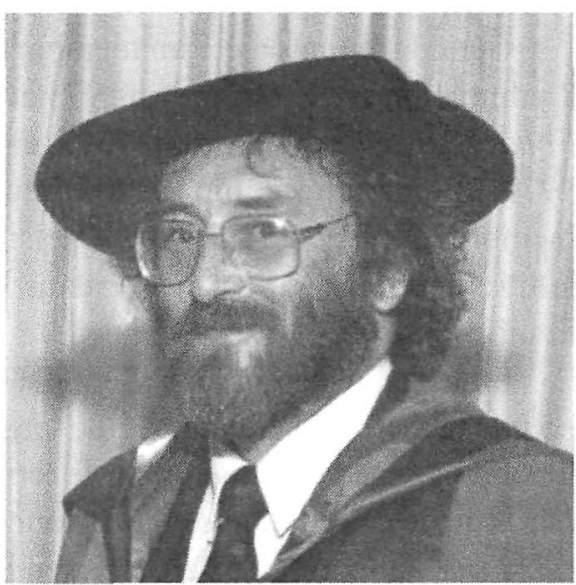

Gracieuseté des Archives de folklore de la Memorial University of Newfoundland. consacrer sa carrière entièrement à la francophonie terre-neuvienne. La petite minorité francophone de Terre-Neuve, composée de quelques milliers d'habitants seulement, avait été négligée par les chercheurs jusqu'à son arrivée.

En 1977, Thomas déposa une thèse de doctorat mettant en parallèle quatre conteurs franco-terreneuviens. Étant à la fois membre des départements d'Études françaises et de Folklore à Memorial, il s'intéressait autant au parler français de Terre-Neuve qu'aux traditions orales. En 1975, il mit sur pied le Centre d'études franco-terreneuviennes, où sont conservés les résultats des enquêtes menées sur la côte ouest de la province.

Gérald Thomas est surtout connu pour ses recherches sur le conte populaire. Auteur de Les Deux Traditions : le conte populaire chez les FrancoTerreneuviens (1983), il a aussi été codirecteur de Studies in Newfoundland 
Folklore : Community and Process (1991). Il a produit une centaine d'articles sur les Franco-Terreneuviens, en plus de présenter les résultats de ses recherches lors d'une multitude de colloques et de conférences. Bien que l'interprétation des contes populaires ait été une de ses grandes préoccupations, il a aussi contribué à l'étude des chansons folkloriques, des devinettes, du blason populaire et de l'histoire orale. Il a d'ailleurs publié en 1999 un ouvrage destiné au grand public intitulé French Family Names of Newfoundland and Labrador.

Entre 1980 et 1992, Thomas a été le promoteur - on pourrait même dire l'imprésario - du grand violoneux terre-neuvien Émile Benoit. Grâce à l'appui de Thomas, Émile Benoit a pu réaliser des disques et faire connaître les FrancoTerreneuviens lors de manifestations culturelles à plusieurs endroits, tant en Amérique du Nord qu'en Europe.

Gérald Thomas a été un membre fondateur de l'Association canadienne d'ethnologie et de folklore en 1975 et il a été rédacteur de la revue Canadian Folklore Canadien de 1985 à 1990, en plus de présider l'association en 19781979. Ethnologue de réputation internationale, il a été élu parmi les 100 membres des Folklore Fellows (Helsinki) en 1995 et il a reçu la même année le titre honoraire de Chevalier dans l'Ordre des palmes académiques de la France.

En tant que professeur, Gérald Thomas savait communiquer sa passion pour la recherche. Pendant plus de vingt ans, il a guidé des groupes d'étudiants lors de voyages d'enquêtes sur le terrain dans la presqu'île de Port-au-Port. Je fus un de ces étudiants et j'ai beaucoup profité de cette chance unique. J'ai aussi participé en 1976 à une excursion à Port-au-Port menée par Gérald Thomas en compagnie de Luc Lacourcière. Le but de ce voyage était de permettre à Lacourcière de connaître une région francophone qu'il n'avait jamais visitée et de rencontrer des informateurs franco-terreneuviens.

Gérald Thomas était un chercheur dévoué et un travailleur infatigable, mais il a aussi été un personnage controversé. Au cours de ses années de retraite, Thomas a continué à étudier la communauté française de Terre-Neuve. Un article intitulé «Les Franco-Terreneuviens après 1960 : une évolution socioculturelle » est paru en 2005 dans le collectif La Modernité en Acadie, alors que son dernier texte, intitulé « La Fête du tchinze d'août », est paru à Saint-Jean, Terre-Neuve, dans le journal Le Gaboteur seulement deux semaines avant son décès. En 2005, il travaillait à un manuscrit dont le sujet était l'analyse du répertoire des contes de Francis Dubois.

Gérald Thomas a été un personnage unique dans le domaine de l'ethnologie. Il a fait l'objet à la fois d'éloges et de critiques pendant sa carrière, mais nul ne pourrait nier qu'il a contribué d'une façon significative 
au développement de l'ethnologie en tant que discipline au Canada. Il est, d'ailleurs, un des ethnologues canadiens dont les recherches ont rayonné le plus au niveau international. Gérald Thomas est décédé le 6 septembre 2005 à l'âge de 65 ans après une brève lutte contre le cancer.

Ronald LABELLE Memorial University of Newfoundland Saint-Jean, Terre-Neuve 